\title{
The cardio-renal-anaemia syndrome predicts survival in peritoneally dialyzed patients
}

Jolanta Malyszko', Edyta Zbroch ${ }^{1}$, Jacek Malyszko ${ }^{1}$, Michal Mysliwiec ${ }^{1}$, Adrian laina ${ }^{2}$

1Department of Nephrology and Transplantology, Medical University, Bialystok, Poland ${ }^{2}$ APC Health-Specialists Clinics, Benei Berak, Israel

Submitted: 30 August 2009

Accepted: 17 November 2009

Arch Med Sci 2010; 6, 4: 539-544

DOI: 10.5114/aoms.2010.14465

Copyright @ 2010 Termedia \& Banach

\begin{abstract}
Introduction: Anaemia is one of the arms of the cardio-renal-anaemia syndrome (CRA) in chronic kidney disease (CKD) patients. The correction of anaemia was effective in the amelioration of both cardiac and renal failure. We studied the relationship between the severity of CRA syndrome in peritoneally dialyzed patients and their survival probability.

Material and methods: Fifty-six patients on peritoneal dialysis were followed for 1 year. Definition of the severity of the CRA in dialysis patients: cardiac arm - NYHA class I-IV $=1-4$ points, renal arm - non-diabetic patients age $<65=1$ point, nondiabetic patients age $>65=2$ points, diabetic patients age $<65=3$ points, diabetic patients age $>65=4$ points, anaemia arm $-\mathrm{Hb} 11-13 \mathrm{~g} / \mathrm{dl}$ (male), $11-12 \mathrm{~g} / \mathrm{dl}($ female $)=1$ point, $\mathrm{Hb} 10-11 \mathrm{~g} / \mathrm{dl}=2$ points, $\mathrm{Hb} 9-10 \mathrm{~g} / \mathrm{dl}=3$ points, $\mathrm{Hb}<9 \mathrm{~g} / \mathrm{dl}=4$ points. The severity score $=$ cardiac + renal + anaemia arms score divided by 3 (maximum 4 points).

Results: A total of 10/56 patients (18\%) died during the study. The median value for the severity score of the whole group was 1.69. In Kaplan-Meier analysis CRA severity score was strongly associated with mortality $(p<0.001)$. It also correlated with albumin, CRP, erythropoietin treatment, $\mathrm{Hb}$ and fasting glucose. In the multivariate regression analysis age, $\mathrm{Hb}$, albumin, and presence of diabetes remained significant predictors of death.

Conclusions: The severity score of CRA syndrome in peritoneally dialyzed patients is an independent and very significant predictor of death. The patients with a high severity score had more hypoalbuminaemia, higher inflammation markers and higher prevalence of diabetes and chronic heart failure. Cardio-renal-anaemia syndrome severity scoring as defined by us could be an easy tool to predict outcome of dialysis patients.
\end{abstract}

Key words: peritoneal dialysis, anaemia, chronic heart failure, diabetes, elderly.

\section{Introduction}

Kidney disease and cardiovascular disease seem to be lethally synergistic and both approach epidemic level, particularly in the elderly [1]. As the population survives to an increasingly older age the number of new cases of congestive heart failure and of end-stage kidney disease is rising steadily. Moreover, these two entities are inexorably linked - indeed they seem to act like Siamese twins. In addition to this combination, there is often a third factor seen in both conditions - anaemia [2]. Cardiovascular disease is a major contributor to mortality and morbidity in patients with chronic renal failure [3]. As the population's life expectancy increases, the
Corresponding author: Prof. Jolanta Malyszko Department of Nephrology and Transplantology Medical University Zurawia 14 15-540 Bialystok, Poland Phone: +48 857409464 Fax: +48 857412391 E-mail: jolmal@poczta.onet.pl 
incidence of both congestive heart failure (CHF) and end-stage renal disease (ESRD) is progressively increasing. Both diseases are inexorably linked. In an era when cardiovascular mortality in developed countries has been declining in the general population, no such reduction in mortality from cardiovascular diseases in patients with end-stage renal disease has been noted. On the contrary, mortality from heart disease of all causes has progressively increased, resulting in approximately $50 \%$ of all deaths and about $30 \%$ of hospitalizations [3]. Chronic heart failure (CHF) is present in more than one-third of incident dialysis patients [4]. Median survival of dialyzed patients with CHF is significantly shorter than without CHF [5]. It is reported to be 36 months compared with 62 months for patients without CHF [5]. Moreover, less than $15 \%$ of dialysis patients with CHF are alive 3 years after hospitalization for CHF [6]. Anaemia is also a common complication of chronic kidney disease (CKD), worsening the survival of this particularly vulnerable population [7]. On the other hand, anaemia is frequently seen in CHF, with a prevalence ranging from $4 \%$ to $55 \%$, depending on the population studied [8]. In an analysis from the SOLVD trial, for example, $22 \%$ of the patients had a haematocrit less than $39 \%$ and $4 \%$ had values below 35\% [9]. A similar rate of anaemia $(17 \%)$ was noted in a population-based cohort of 12,065 patients with newly diagnosed CHF [10]. The incidence of anaemia appears to increase with worsening functional class, from $9 \%$ for NYHA class I, to $79 \%$ for NYHA class IV [11]. Moreover, anaemia in $\mathrm{CHF}$ patients has been associated with increased mortality and number of hospitalizations and a greater severity of $\mathrm{CHF}$, relative to non-anaemic subjects [12].

Taking all these data into consideration, we aimed to study possible relations between cardiorenal-anaemia syndrome (CRA) in peritoneally dialyzed patients and their survival probability.

\section{Material and methods}

The study was performed on 56 prevalent chronic ambulatory peritoneal dialysis (CAPD) patients (mean age $56 \pm 17$ years, time on dialysis $31 \pm 14$ months). In CAPD patients renal failure was due to glomerulonephritis $(n=17)$, chronic interstitial nephritis $(n=4)$, polycystic kidney disease $(n=6)$, diabetes ( $n=18$ ), others (lupus nephritis $n=2$, nephrolithiasis $n=1$, reflux nephropathy $n=2$, hypertensive nephropathy $n=2)$ or unknown $(n=4)$. Dialysis adequacy was assessed by measuring Kt/V (mean Kt/V - $2.13 \pm 0.34$ ). Forty-four patients were treated with recombinant human erythropoietin and 45 with hypotensive drugs. Twenty-one patients were anuric, in 35 residual renal function was present (daily urine volume ranged from $300 \mathrm{ml}$ to $2400 \mathrm{ml}$, median $1460 \mathrm{ml} /$ day). In all CAPD patients blood was drawn in the morning between $8.00 \mathrm{am}$ and $9.00 \mathrm{am}$ when they appeared for routine examination at the outpatient unit after overnight fast. Blood was taken without stasis. Samples were aliquoted and stored at $-40^{\circ} \mathrm{C}$ up to one month before assay. The patients' height and weight were recorded for all groups. All the patients were informed about the aim of the study and gave their consent. The study was approved by the Medical University Ethics Committee. All the parameters were measured by means of standard laboratory methods. hsCRP was assayed using commercially available kits from American Diagnostica, New Haven, Ct, USA. Heart failure severity was assessed using NYHA class. Definition of the severity of CRA in dialysis patients: cardiac arm - NYHA class I-IV = 1-4 points, renal arm - non-diabetic patients age $<65=1$ point, nondiabetic patients age $>65=2$ points, diabetic patients age $<65=3$ points, diabetic patients age $>65=4$ points, anaemia arm - haemoglobin $(\mathrm{Hb}) 11-13 \mathrm{~g} / \mathrm{dl}$ (male), 11-12 g/dl (female) = 1 point, $\mathrm{Hb} 10-11 \mathrm{~g} / \mathrm{dl}=2$ points, $\mathrm{Hb} 9-10 \mathrm{~g} / \mathrm{dl}=3$ points, $\mathrm{Hb}<9 \mathrm{~g} / \mathrm{dl}=4$ points. The severity score $=$ cardiac + renal + anaemia arms score divided by 3 (maximal 4 points).

Data were analysed using Statistica 7.0 computer software. Normality of variable distribution was tested using Shapiro-Wilk W-test. If data were not distributed normally, they were logarithmically transformed to achieve normal distribution (hSCRP). Data were reported as means \pm SD. Student's t-test or Mann-Whitney $U$ test was used to compare differences between groups with $p<0.05$ considered statistically significant, when appropriate. Patient survival was estimated using the Kaplan-Meier method and groups compared using the log-rank test. Candidate risk factors with a $p$-value $<0.1$ in the univariate analysis were considered for the multivariable model.

\section{Results}

Basal clinical and biochemical characteristics are presented in Table I. The median value for the severity score of the whole group of dialysis patients was 1.69. Patients with a median above 1.69 were significantly older, with higher NYHA class, lower haemoglobin, higher fasting glucose and hsCRP, and lower albumin. Diabetes was also more prevalent in this population ( $60 \%$ vs. $10 \%, p<0.001)$. Systolic blood pressure was $140 \pm 23 \mathrm{mmHg}$, whereas diastolic blood pressure was $84 \pm 12 \mathrm{~mm} \mathrm{Hg}$. Only $22 \%$ of patients reached target blood pressure of $130 / 80 \mathrm{mmHg}$.

The most commonly used hypotensive drugs in the peritoneal dialysis (PD) population were: $\beta$-blockers (83\%), calcium channel blockers (68\%), angiotensin convertase enzyme (ACE) inhibitors 
Table I. Basal clinical characteristics of the studied groups

\begin{tabular}{|c|c|c|}
\hline Parameter & CRA $>1.69, n=25$ & CRA $<1.69, n=31$ \\
\hline Age [years] & $66.38 \pm 12.10^{\star * *}$ & $48.32 \pm 14.01$ \\
\hline BMI $\left[\mathrm{kg} / \mathrm{m}^{2}\right]$ & $24.9 \pm 4.5$ & $24.3 \pm 4.9$ \\
\hline $\mathrm{Ht}[\%]$ & $32.45 \pm 4.24^{\star * \star}$ & $38.74 \pm 3.93$ \\
\hline $\mathrm{Hb}[\mathrm{g} / \mathrm{dl}]$ & $11.27 \pm 1.55^{\star \star}$ & $12.19 \pm 1.11$ \\
\hline Erythrocyte count $\left[\times 10^{6} / \mu \mathrm{l}\right]$ & $3.70 \pm 0.54^{*}$ & $4.16 \pm 0.47$ \\
\hline Leukocyte count $\left[\times 10^{3} / \mu \mathrm{l}\right]$ & $7.92 \pm 2.52$ & $5.98 \pm 1.83$ \\
\hline$M C V[f l]$ & $91.42 \pm 4.45$ & $91.28 \pm 6.28$ \\
\hline Platelet count $\left[\times 10^{3} / \mu \mathrm{l}\right]$ & $236.33 \pm 79.52$ & $214.87 \pm 42.54$ \\
\hline Iron [ug/dl] & $57.43 \pm 13.37$ & $62.08 \pm 29.89$ \\
\hline $\mathrm{TIBC}[\mu \mathrm{g} / \mathrm{dl}]$ & $194.00 \pm 48.89$ & $224.92 \pm 46.26$ \\
\hline Ferritin [ng/ml] & $315.09 \pm 249.85$ & $250.98 \pm 184.61$ \\
\hline $\mathrm{hsCRP}[\mathrm{mg} / \mathrm{l}]$ & $11.80 \pm 9.21^{* *}$ & $4.95 \pm 3.98$ \\
\hline Total protein [g/dl] & $6.36 \pm 0.47$ & $6.72 \pm 0.57$ \\
\hline Albumin [g/dl] & $3.39 \pm 0.42^{\star}$ & $3.80 \pm 0.49$ \\
\hline Glucose [mg/dl] & $124.18 \pm 47.59^{*}$ & $99.07 \pm 36.31$ \\
\hline Calcium [mmol/l] & $2.19 \pm 0.25$ & $2.14 \pm 0.26$ \\
\hline Phosphate [mg/dl] & $5.14 \pm 1.31$ & $4.91 \pm 1.48$ \\
\hline NYHA class & $3.04 \pm 0.74$ & $1.42 \pm 0.50$ \\
\hline rHuEPO dose [IU/week] & $4540 \pm 3335^{*}$ & $3083 \pm 2799$ \\
\hline CRA severity score & $2.46 \pm 0.54^{\star \star *}$ & $1.17 \pm 0.33$ \\
\hline
\end{tabular}

Values given are means $\pm S D,{ }^{*} p<0.05,{ }^{* *} p<0.01,{ }^{* *} p<0.001$ CRA $>1.69$ vs. CRA $<1.69$

(66\%) and diuretics (37\%) with mean number of hypotensive of 3 . Only 2 patients did not require hypotensive drugs to control blood pressure. All of the patients were treated with ESA, except 7 subjects. All of them were given iron supplements, folic acid, and phosphate binders.

A total of 10 out of 56 patients (18\%) died during the study (9 due to cardiovascular disease). In Kaplan-Meier analysis CRA severity score was strongly associated with mortality $(p<0.001$, Figure 1). The severity score was also correlated with albumin $(r=-0.38, p<0.05)$, C-reactive protein (CRP) $(r=0.30, p<0.05)$, erythropoietin treatment $(r=0.33, p<0.05), \mathrm{Hb}(r=-0.72, p<0.001)$, age $(r=0.60, p<0.001)$, NYHA class $(r=0.82, p<0.001)$, presence of diabetes $(r=0.61, p<0.001)$ and fasting glucose $(r=0.30, p<0.05)$. In the multivariate regression analysis age (HR $1.91,95 \% \mathrm{Cl}$ $1.28-2.94, p<0.001$ ), haemoglobin (HR 1.16, $95 \% \mathrm{Cl}$ $1.08-1.44, p<0.05$ ), albumin (HR $1.19,95 \% \mathrm{Cl}$ $0.50-0.96, p<0.01$ ), and presence of diabetes (HR $1.29,95 \% \mathrm{Cl} 1.28-1.99, p<0.001)$, remained significant predictors of death. If we exclude all the components of the CRA scoring system, the only predictor of death was albumin (HR $3.1495 \% \mathrm{Cl}$ $0.23-0.69, p<0.001$ ).

\section{Discussion}

In the present study we assessed the relationship between the severity of CRA syndrome in chronic peritoneally dialyzed patients and survival probability. We found that the severity score of CRA syndrome in peritoneally dialyzed patients was an

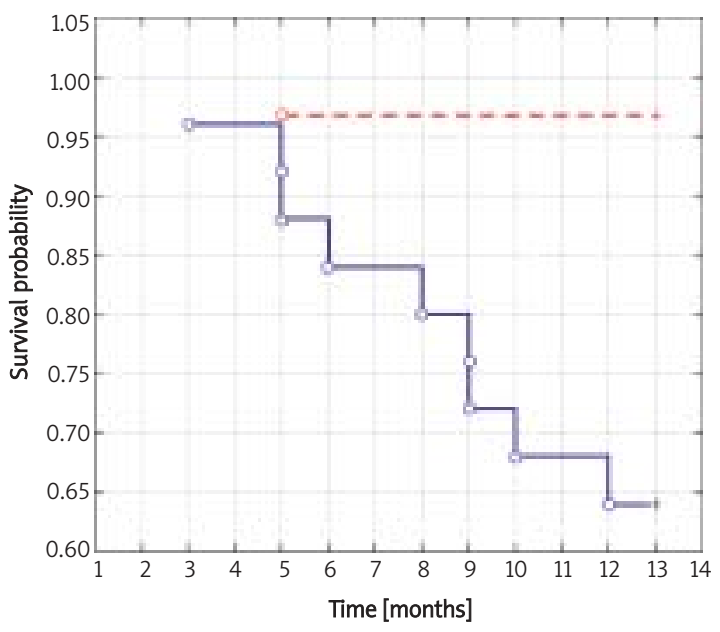

$\checkmark$ survived $=$ dead $\quad$ CRA score below 1.69

- - CRA score over 1.69

Figure 1. Kaplan-Meier survival curve in peritoneally dialysed patients 
independent and very significant predictor of death. In addition, patients with a high severity score had more hypoalbuminaemia and higher inflammation markers, and certainly were more anaemic and diabetic, with higher NYHA class. To the authors' knowledge, this is the first report on the relationship between anaemia, CHF severity, diabetes and mortality in a PD population. In our population $34 \%$ of patients were in NYHA class III or IV. The overall prevalence of $\mathrm{CHF}$ in this population was $62 \%$. In a study of the Medicare population of the USA, patients with either CKD or diabetes were at much greater risk of developing atherosclerotic vascular disease, CHF or ESRD over a 2-year period [13]. Combination of CKD and diabetes increased the risks even further, with prevalence of $\mathrm{CHF}$ in this population at $54.1 \%$ [13]. On an absolute basis, however, the high death rates of patients with CKD may reflect accelerated rates of atherosclerotic vascular disease and congestive heart failure. Large observational studies examining the association between anaemia and "hard" clinical outcomes are rare in patients with CKD. In another study by Li et al. [14] using the General Medicare 5\% Denominator Files $49 \%$ of CKD patients older than 67 years were anaemic. Anaemia was associated with age, female gender, black race and other co-morbid conditions including $\mathrm{CHF}$, gastrointestinal bleeding, and liver disease. Anaemic patients were more prone to atherosclerotic vascular disease, ESRD, death, CHF and hospitalization. In our study anaemia was a part of CRA syndrome and subjects with a higher CRA severity score had lower haemoglobin; also, haemoglobin was one of the strongest predictors of death in our population. Silverberg et al. [15] in their review called CRA syndrome a vicious circle of destruction. The combined presence of these three diseases increases the risks of mortality, morbidity and hospitalization. They are also associated with an increase in at least four mechanisms than can damage the tissues: an increase in sympathetic activity, an increase in renin-angiotensinaldosterone system (RAAS) activity, and an enhancement of oxidative stress and inflammation [16]. In addition, more worrisome is the fact that all the mechanisms can activate each other and destroy the body's cells. In our study we found that albumin, a negative marker of inflammation, was a predictor of death. Anaemia is more prevalent in advanced CHF. From previous studies in CHF patients, it has been noted that anaemia may be incidental or directly related to CHF itself. Increased circulating cytokines, haemodilution, iron deficiency, the use of ACE inhibitors, renal dysfunction, poor nutrition and decreased bone marrow perfusion may all contribute to the development of anaemia in this population [17-19]. However, after several trials, including the SOLVD, ELITE II, COPERNICUS, CHARM,
VAL-HEFT and others, anaemia was recognized as an important risk factor for mortality and morbidity in CHF patients [20-22]. Anaemia in CHF is also often associated with decreased renal function, more rapid deterioration of kidney disease, and signs of malnutrition and inflammation, such as low body mass index (BMI), low serum albumin, low serum total protein, low serum cholesterol, increased CRP and deranged adrenal steroid metabolism characteristic of catabolism, as quantified by the cortisol [23-25]. The odds ratios of (OR) mortality and hospitalization in patients with anaemia are similar to those of four other common cardiovascular risk factors: smoking, diabetes mellitus, hypertension and hypercholesterolaemia. It is for this reason that we have called anaemia "the fifth cardiovascular risk factor", after the other four risk factors [26, 27].

There are very limited reports on cardiovascular risks factor in the PD population. In a recent study from Latin America on 298 prevalent PD patients, systolic heart failure was strongly associated with diabetes and hypoalbuminaemia [28], factors we found to be strong predictors of mortality. In addition, anaemia was associated significantly with left ventricular hypertrophy. To address the highly complex interrelated nature of CKD and diabetes, hypertension, and cardiovascular disease, Collins et al. [29] examined CKD prevalence by the predictive effect of demographic factors, comorbid conditions, and CKD risk factors by using National Health and Nutrition Examination Survey (NHANES) 1999-2004 data. They found that CKD prevalence increased with age, and was greater in diabetes, the greatest for diabetes and hypertension. Age and diabetes were also strong predictors of death in our PD population. In Japan, from among 327 ESRD patients initiated on PD from April 1995 to March 2005 in the Kidney and Dialysis Centre, Saitama Medical School, 8 developed de novo cardiovascular and cerebrovascular complications. No significant differences were observed in blood pressure, CTR, haemoglobin, total cholesterol, triglycerides, or $\mathrm{HbA}_{1 \mathrm{c}}$ between the groups. A decrease in serum albumin after commencement of dialysis is an important risk factor for, and a strong predictor of, vascular complications in patients on PD [30]. In the multicentre cross-sectional study, performed to evaluate the prevalence of heart failure (HF) and the associated cardiovascular (CV) risk factors in 298 PD patients from Argentina and Uruguay, the prevalence of $\mathrm{CV}$ risk factors was $73 \%$ hypertension, $51 \%$ sedentarism, $18 \%$ diabetes, $16.8 \%$ obesity, $12 \%$ smokers, $42.3 \%$ phosphorus > $5.5 \mathrm{mg}$ per $100 \mathrm{ml}$, $42.3 \%$ parathyroid hormone $>300 \mathrm{pg} / \mathrm{ml}$, and $29.6 \%$ calcium phosphate product $>55$. Variables associated with LVH in the multivariate analysis were anaemia $(\mathrm{OR}=4.06, p<0.001)$ and previous 
haemodialysis $(\mathrm{OR}=1.99, p<0.031)$. In a single Colombian centre, using a retrospective cohort study, survival and mortality risk factors in the dialysis population were evaluated. For peritoneal dialysis patients, the significant risk factors were diabetes mellitus $(p=0.01)$ and albumin $<2.5 \mathrm{~g} / \mathrm{dl}$ $(p=0.02)[31]$.

\section{References}

1. US Renal Data System: USDRS 2008 Annual Data Report. Bethesda, MD. National Institute of Health, National Institute of Diabetes and Digestive and Kidney Diseases. 2009. Available at: www.usrds.org.

2. Foley RN, Parfrey PS, Harnett JD, Kent GM, Murray DC, Barre PE. The impact of anemia on cardiomyopathy, morbidity, and and mortality in end-stage renal disease. Am J Kidney Dis 1996; 28: 53-61.

3. Sarnak MJ, Levey AS, Schoolwerth AC, et al.; American Heart Association Councils on Kidney in Cardiovascular Disease, High Blood Pressure Research, Clinical Cardiology, and Epidemiology and Prevention. Kidney disease as a risk factor for development of cardiovacular disease: a statement from the American Heart Association Councils on Kidney in Cardiovascular Disease, High Blood Pressure, Clinical Cardiology, and Epidemiology and Prevention. Circulation 2003; 108: 2154-69.

4. Stack AG, Bloembergen WE. A cross-sectional study of the prevalence and clinical correlates of congestive heart failure among incident US dialysis patients. Am J Kidney Dis 2001; 38: 992-1000.

5. Harnett JD, Foley RN, Kent GM, Barre PE, Murray D, Parfrey PS. Congestive heart failure in dialysis patients: prevalence, incidence, prognosis and risk factors. Kidney Int 1995; 47: 884-90.

6. Trespalacios FC, Taylor AJ, Agodoa LY, Bakris GL, Abbott KC. Heart failure as a cause for hospitalization in chronic dialysis patients. Am J Kidney Dis 2003; 41: 1267-77.

7. Levin A. Anemia and left ventricular hypertrophy in chronic kidney disease populations: a review of the current state of knowledge. Kidney Int Suppl 2002; 80: 35-8.

8. Felker GM, Adams KF Jr, Gattis WA, O'Connor CM. Anemia as a risk factor and therapeutic target in heart failure. J Am CollCardiol 2004; 44: 959-66.

9. Al-Ahmad A, Rand WM, Manjunath G, et al. Reduced kidney function and anemia as risk factors for mortality in patients with left ventricular dysfunction. J Am Coll Cardiol 2001; 38: 955-62.

10. Ezekowitz JA, McAlister FA, Armstrong PW. Anemia is common in heart failure and is associated with poor outcomes: insights from a cohort of 12065 patients with new-onset heart failure. Circulation 2003; 107: 223-5.

11. Silverberg DS, Wexler D, Blum M, et al. The use of subcutaneous erythropoietin and intravenous iron for the treatment of the anemia of severe, resistant congestive heart failure improves cardiac and renal function and functional cardiac class, and markedly reduces hospitalizations. J Am Coll Cardiol 2000; 35: 1737-44.

12. Silverberg DS, Wexler D, laina A, Steinbruch S, Wollman Y, Schwartz D. Anemia, chronic renal disease and congestive heart failure - the cardio renal anemia syndrome: the need for cooperation between cardiologists and nephrologists. Int Urol Nephrol 2006; 38: 295-310.
13. Foley RN, Murray AM, Li S, et al. Chronic kidney disease and the risk for cardiovascular disease, renal replacement, and death in the United States Medicare population, 1998 to 1999. J Am Soc Nephrol 2005; 16: 489-95.

14. Li S, Foley RN, Collins AJ. Anemia and cardiovascular disease, hospitalization, end stage renal disease, and death in older patients with chronic kidney disease. Int Urol Nephrol 2005; 37: 395-402.

15. Silverberg DS, Wexler D, laina A, Steinbruch S, Wollman Y, Schwartz D. Anemia, chronic renal disease and congestive heart failure - the cardio renal anemia syndrome: the need for cooperation between cardiologists and nephrologists. Int Urol Nephrol 2006; 38: 295-310.

16. Bongartz LG, Cramer MJ, Doevendans PA, Joles JA, Braam B. The severe cardiorenal syndrome: "Guyton revisited". Eur Heart J 2005; 26: 11-7.

17. Ishani A, Weinhandl E, Zhao Z, et al. Angiotensinconverting enzyme inhibitor as a risk factor for the development of anemia, and the impact of incident anemia on mortality in patients with left ventricular dysfunction. J Am Coll Cardiol 2005; 45: 391-9.

18. van der Meer P, Lipsic E, Westenbrink BD, et al. Levels of hematopoiesis inhibitor $\mathrm{N}$-acetyl-seryl-aspartyl-lysylproline partially explain the occurrence of anemia in heart failure. Circulation 2005; 112: 1743-7.

19. Anand IS. Anemia and chronic heart failure implications and treatment options. J Am Coll Cardiol 2008; 52: 501-11.

20. Silverberg DS, Wexler D, Blum M, et al. The interaction between heart failure, renal failure and anemia-the cardiorenal anemia syndrome. Blood Purif 2004; 22: 277-84.

21. Silverberg DS, Wexler D, laina A. The role of anemia in the progression of congestive heart failure. Is there a place for erythropoietin and intravenous iron? J Nephrol 2004; 17: 749-61.

22. Wexler D, Silverberg DS, Sheps D, et al. Prevalence of anemia in patients admitted to hospital with a primary diagnosis of congestive heart failure. Int I Cardiol 2004; 96: 79-87.

23. Silverberg DS, Wexler D, Palazzuoli A, laina A, Schwartz D. The anemia of heart failure. Acta Haematol 2009; 122: 109-19.

24. laina A, Silverberg DS, Wexler D, laina Nomy L. The cardiorenal anemia syndrome. Med Pregl 2007; 60 Suppl 2: 145-50.

25. Palazzuoli A, Gallotta M, lovine F, Nuti R, Silverberg DS. Anaemia in heart failure: a common interaction with renal insufficiency called the cardio-renal anaemia syndrome. Int J Clin Pract 2008; 62: 281-6.

26. Silverberg DS, Wexler D, Blum M, Schwartz D, Wollman Y, laina A. Erythropoietin should be part of congestive heart failure management. Kidn Int Suppl 2003; 87: S40-7.

27. Hunt SA, Abraham WT, Chin et al.; American College of Cardiology Foundation; American Heart Association. 2009 Focused Update Incorporated Into the ACC/AHA 2005 Guidelines for the Diagnosis and Management of Heart Failure in Adults. A Report of the American College of Cardiology Foundation/American Heart Association Task Force on Practice Guidelines Developed in Collaboration With the International Society for Heart and Lung Transplantation. J Am Coll Cardiol 2009; 53: e1-90.

28. Moretta G, Locatelli AJ, Gadola L, et al. Rio de La Plata study: a multicenter, cross-sectional study on cardiovascular risk factors and heart failure prevalence in peritoneal dialysis patients in Argentina and Uruguay. Kidney Int Suppl 2008; 108: S159-64.

29. Collins AJ, Vassalotti JA, Wang C, et al. Who should be targeted for CKD screening? Impact of diabetes, 
hypertension, and cardiovascular disease. Am J Kidney Dis 2009; 53 (3 Suppl 3): S71-7.

30. Arima H, Nakamoto H, Okada S, et al. Risk factors for vascular complications in patients on peritoneal dialysis. Adv Perit Dial 2006; 22: 192-7.

31. Enríquez J, Bastidas M, Mosquera M, et al. Survival on chronic dialysis: 10 years' experience of a single Colombian center. Adv Perit Dial 2005; 21: 164-7. 